\title{
VARIACION DEL METODO DE SECADO EN LA FERMENTACION ESPONTANEA DE ALMIDON NATIVO DE YUCA
}

\section{VARIATION OF THE DRY METHOD IN THE SPONTANEOUS FERMENTATION OF NATIVE YUCA STARCH}

\author{
Serna Fadul Tiana ${ }^{1},{ }^{*}$ Contreras SincelejoYucelys ${ }^{1}$ Lozano Polo Maria ${ }^{1}$; Salcedo Mendoza \\ Jairo', Hernández Ruydiaz Jorge ${ }^{1}$
}

${ }^{1}$ Universidad de Sucre / Programa de Ingeniería Agroindustrial / Procesos Agroindustriales y Desarrollo Sostenible "PADES" / Semillero de Investigación Agroindustria, Desarrollo e Investigación "SIADI" / Sincelejo - Colombia. Correo electronico: inagro.tiana@gmail.com, yucelyscontreras@gmail.com,mariajoselozano96@gmail.com, Jairo.salcedo@unisucre.edu.co, jorge.hernandez@unisucre.edu.co

Recibido: 25 de marzo de 2017; aprobado 25 de mayo de 2017

\section{RESUMEN}

El almidón agrio de yuca es un producto que se obtiene por fermentación espontanea a partir del almidón nativo, ampliamente utilizado en la elaboración de productos horneados por su especial funcionalidad de expandir masas de panadería. En Colombia, el proceso de obtención de almidón agrio es realizado de forma tradicional en pequeñas empresas "rallanderias", con un mínimo de control de las variables que intervienen en el proceso. El objetivo de esta investigación fue evaluar el efecto de algunas variables del 
proceso de fermentación, como el enriquecimiento del medio fermentativo adicionando jarabe de glucosa (JG) y extracto de levadura (EL) en diferentes concentraciones y la aplicación de un método de secado con humidificación periódica comparado con el secado solar tradicional. Además, se evaluó la calidad del almidón agrio mediante la determinación del índice de absorción de agua (IAA), índice de solubilidad (ISA), poder de hinchamiento $(\mathrm{pH})$ y capacidad de expansión, por medio de la elaboración de producto de panificación del tipo pandebono. Los resultados muestran que la incorporación de JG y $E L$ afectaron significativamente $(p<0,05)$ con un incremento en la capacidad de expansión, proporcional al aumento de los días de fermentación, ligado a un descenso de $\mathrm{pH}$; obteniéndose los mejores resultados en la calidad del almidón agrio después de los días 21 de fermentación. El secado con humidificación presentó el mayor volumen de expansión del almidón. Con esta investigación se logró definir variables de proceso de producción de almidón agrio que permitieron mejorar la expansión del pan de bono.

Autor a quien dirigir la
correspondencia: *Contreras Sincelejo Yucelys, Correo electronico: yucelyscontreras@gmail.com
Palabras clave: Almidón, expansión, fermentación, humidificación.

\section{ABSTRACT}

Sour cassava starch is a product obtained by spontaneous fermentation from native starch, widely used in the preparation of baked goods due to its special functionality of expanding bakery doughs. In Colombia, the process of obtaining sour starch is carried out traditionally in small "rallanderias" companies, with a minimum of control of the variables that intervene in the process. The objective of this research was to evaluate the effect of some variables of the fermentation process, such as the enrichment of the fermentation medium by adding glucose syrup (JG) and yeast extract (EL) in 
different concentrations and the application of a drying method with humidification Periodic compared to traditional solar drying. In addition, the quality of the sour starch was evaluated by determining the water absorption index (IAA), solubility index (ISA), swelling power (PH) and expansion capacity, by means of the preparation of the bakery product. pandebono type. The results show that the incorporation of JG and EL significantly affected $(p<0.05)$ with an increase in the expansion capacity, proportional to the increase in fermentation days, linked to a decrease in $\mathrm{pH}$; obtaining the best results in the quality of the sour starch after the 21 days of fermentation. Drying with humidification showed the highest expansion volume of the starch. With this research it was possible to define variables of sour starch production process that allowed to improve the expansion of the bonus bread.

Key words: Starch, fermentation, expansion, humidification

\section{INTRODUCCIÓN}

El almidón agrio de yuca se obtiene mediante reacciones ácidas y de hidrólisis parcial del almidón nativo ocasionada por la actividad enzimática de microorganismos amilolíticos propios de un proceso de fermentación anaerobia, que luego de un secado al sol modifican su estructura (Alarcon M \& Dufuor). En Colombia, este almidón fermentado es ampliamente empleado en la elaboración de productos horneados como pandeyuca, pandebono, besitos y rosquillas (Rincon Suarez \& Villamil Novoa, 2005). Las etapas claves del proceso de producción de este producto son la fermentación y el secado, en donde se genera la capacidad de expansión deseable en la panificación, la cual no se pude obtener con un almidón sin fermentar y sin secar (Lopez Marin, 2011). Los gránulos de almidón son modificados por enzimas y ácidos orgánicos durante la fermentación y posterior secado al sol, la luz solar contribuye a la generación de compuestos oxidados y al cumplimiento de las características peculiares de las dextrinas que tienen diferentes grados de polimerización y gránulos de almidón perforados, que mejoran la estructura del almidón de yuca agria tradicional (Marcon $\mathrm{M}$, Kurtza, \& Raguzzoni, 2009 ). Durante el secado solar, el contenido de ácido láctico 
disminuye, lo cual sugiere que se da una reacción fotoquímica que involucra al almidón, esto resulta en la formación de una red tridimensional que retiene las burbujas de aire durante el horneo y, por lo tanto, explican el potencial para panificación de este producto ( Cadena, Villarraga, Deivis , \& salcedo, 2006).

La fermentación es un proceso efectivo en la eliminación de los compuestos ciánicos endógenos de la yuca, luego de proceso tradicional de fermentación, el contenido de glucósidos cianógenos (Linamarina y Lotaustralina) es reducido casi completamente debido principalmente a la acción de las enzimas de la bacterias acido lácticas encargadas de este proceso (Kobawila, Louembe, Keleke, Hounhouigan, \& Gamba, 2005). Durante la fermentación se presentas cambios en la disminución en el $\mathrm{pH}$, formación de ácidos orgánicos, ataque por enzimas amilolíticas, disminución del poder de hinchamiento y viscosidad $y$ aumento de la solubilidad del almidón de yuca (Ramirez Ascheri \& Rivero Vilela, 1995). Algunos investigadores han evaluado el efecto de la adición de nutrientes sobre la calidad del almidón. (Maria, y otros, 2007) y (Marcon M. A., 2004), plantearon que la adición de jarabe de glucosa al proceso de fermentación del almidón de mandioca podría reducir significativamente el tiempo de fermentación, como una alternativa importante para acelerar el proceso de fermentación de almidón de yuca en regiones frías, sin que se afectara la calidad del producto final, determinada por el poder de panificación, lo que hizo más eficiente la obtención de almidón agrio. En este sentido, se evaluara el efecto de la adición de sustratos con fuente de carbono y nitrógeno durante la fermentación espontanea del almidón nativo de yuca y cómo influye el método de secado empleado en la calidad final del almidón agrio evaluado en un producto de panificación.

\section{METODOLOGIA}

Montaje fermentativo de almidón nativo de yuca (Manihot esculenta C.): El almidón nativo de yuca se sometió a un proceso de fermentación espontanea, en estado estacionario y temperatura ambiente durante 60 días. Este se llevó a cabo en biorreactores de 10 litros de capacidad manteniendo una relación de almidón/agua de 1/1,5 utilizando agua no tratada obtenida en las instalaciones de la universidad de Sucre sede granja el perico. Se adicionaron jarabe de glucosa a concentraciones de $0 \%, 0,50 \%$ y $0,75 \% \mathrm{p} / \mathrm{p}$ y extracto de levadura a concentraciones de $0 \%, 0,50 \%$ y $0,70 \%$ p/p. La fermentación 
para cada uno de los tratamientos fue monitoreada por medio de mediciones de $\mathrm{pH}$ cada 10 días dentro del medio de fermentación. También se realizó un secado al sol a temperatura ambiente de las muestras de almidón cada 10 días en un periodo entre 6 a 8 horas.

Método de secado: El proceso de secado se llevó a cabo por medio de dos métodos, un secado con humidificación M1, comparado con el secado solar tradicional M2. El secado con humidificación consistió en determinar la cantidad de agua retenida en el almidón antes de iniciado el secado (almidón húmedo) inicialmente, luego se registró la hora inicio de secado y al cabo de 3 horas se roseo el almidón con el $50 \%$ de la cantidad de agua calculada aproximadamente en el almidón (Brabet, Chuzel, Dufour, Raimbault, \& Giraud); en el secado solar tradicional se registró el tiempo de secado total por día de secado. Para ambos métodos de secado se suspendió el secado al alcanzar el almidón humedades finales entre $10 \%$ y $12 \%$.

Análisis propiedades funcionales: Una vez obtenido el almidón agrio se determinó índice de absorción de agua (IAA), índice de solubilidad (ISA) y poder de hinchamiento $(\mathrm{pH})$ según la metodología descrita por (Anderson, Conway, Pheiser, \& Griffin, 1969) con algunas modificaciones por temperatura e gelatinización del almidón. De estos resultados se realizan cada uno de los cálculos requeridos para obtener: IAA (g gel/ $\mathrm{g}$ almidón), ISA (g solubles/g almidón) y pH (g agua/g almidón). Salcedo et al., (2017).

$$
I A A=\frac{\text { Peso gel }(g)}{\text { Peso muestra }(g)}
$$

$$
I S A=\frac{\text { Solidos en el sobrenadante }(g)}{\text { Peso muestra }} * 100
$$

$$
P S=\frac{\text { Peso del gel }(g)}{\text { Peso muestra }(g)-\text { Peso soluble }(g)}
$$

Capacidad de expansión: Se evaluó la capacidad de expansión del almidón mediante la elaboración de un producto de panificación conocido tradicionalmente como pan de bono, en la tabla 1 se muestra la formulación estandarizada para la elaboración del producto bajo una base de queso del 100 gramos. En una mezcladora de tres velocidades (CI TALSA, SM.101) inicialmente se mezclaron los ingredientes secos durante 1 minuto a velocidad 1, luego los húmedos durante 5 minutos manteniendo la misma velocidad. Posteriormente fueron horneados a $190{ }^{\circ} \mathrm{C}$ durante 15 min en horno para panificación (PIRON, P524RUD).La capacidad de expansión fue determinada basados en el volumen de desplazamiento de semillas, utilizando una probeta de 500 $\mathrm{mL}$ y granos de ajonjolí como "partículas 
sólidas" de referencia (Aquino, Pereira, Watanabe, \& Amante, 2013). El volumen específico se expresó como la relación volumen/peso del producto de panificación $\left(\mathrm{cm}^{3} / \mathrm{g}\right)$.

Tabla 1. Formulación de Pandebono a partir de almidón de yuca.

\begin{tabular}{|c|c|}
\hline Ingredientes & Cantidad \\
\hline Almidón & $33,4 \mathrm{~g}$ \\
\hline Azúcar & $8,3 \mathrm{~g}$ \\
\hline Mantequilla & $7,6 \mathrm{~g}$ \\
\hline Queso & $100 \mathrm{~g}$ \\
\hline Agua & c.n. $\approx 40 \mathrm{ml}$ \\
\hline
\end{tabular}

Análisis estadístico: Para el análisis estadístico fue empleado un diseño multifactorial categórico. El primer factor corresponde al tiempo de fermentación con seis niveles establecidos a partir del día inicial de fermentación, en intervalos de diez días hasta la finalización del proceso fermentativo (días: 10, 20, 30, 40, 50, 60). El segundo factor hace referencia a la concentración de sustrato con tres niveles definidos como T0, T1 y T2 como se describe en la tabla 2. El tercer factor denota el método de secado empleado con dos niveles definidos como el secado solar tradicional y el secado con humidificación (M2 y M1, respectivamente). Los resultados se estudiaron estadísticamente mediante análisis de datos conglomerados (clúster), análisis de varianza y test de comparación de medias determinado mediante prueba de Tukey a un nivel de 5\% significancia utilizando el software Statgraphics Centurion XVI (versión 16.1.18).

Tabla 2. Descripción de tratamientos de fermentación realizados

\begin{tabular}{|c|c|c|}
\hline \multirow{2}{*}{$\begin{array}{c}\text { Tratamient } \\
0\end{array}$} & \multicolumn{2}{|c|}{ Concentración de sustratos } \\
\hline & $\begin{array}{c}\text { [Jarabe de } \\
\text { Glucosa] }\end{array}$ & $\begin{array}{c}\text { [Extracto de } \\
\text { levadura] }\end{array}$ \\
\hline T0 & \multicolumn{2}{|c|}{$\begin{array}{c}\text { Control sin sustratos: } \\
\text { Almidón + Agua }\end{array}$} \\
\hline T1 & 0,50 & 0,50 \\
\hline T2 & 0,75 & 0,70 \\
\hline
\end{tabular}

\section{RESULTADOS Y DISCUSION}

Propiedades fisicoquímicas: El almidón agrio es un producto de bajo $\mathrm{pH}$, alto factor ácido y baja viscosidad, características que son causadas por la disminución en el grado de polimerización que produce la hidrólisis durante la fermentación (Bertolini, Mestres, 
Raffi, Buléon, Lerner, \& Colonna, 2001). En la Figura 1 podemos observar el comportamiento del pH de acuerdo a los días de fermentación y concentraciones de sustrato.

Al adicionar sustratos como JG y EL, se observa una disminución significativa $(p<0,05)$ en el $\mathrm{pH}$ del medio fermentativo respecto al control. Resultados acordes con los reportados por (Marcon M. A., 2004) quienes argumentan que la presencia de una fuente de carbono acelera la actividad biocatalítica de bacterias acido-lácticas, responsables en la conversión de azúcares reductores en ácidos orgánicos, especialmente ácido láctico.

El pH del medio disminuye significativamente en el tiempo $(p<0,05)$ alcanzando un equilibrio después de 21 días de fermentación, a partir del cual empiezan a registrarse disminuciones proporcionales a los días, especialmente en los tratamientos con adición de sustratos. (Ramirez Ascheri \& Rivero Vilela , 1995), Afirman que la reducción del $\mathrm{pH}$ durante el proceso de fermentación podría corresponder a la liberación de ácidos orgánicos y compuestos aromáticos yuca, resultados acordes a los obtenidos en la fermentación descrita.

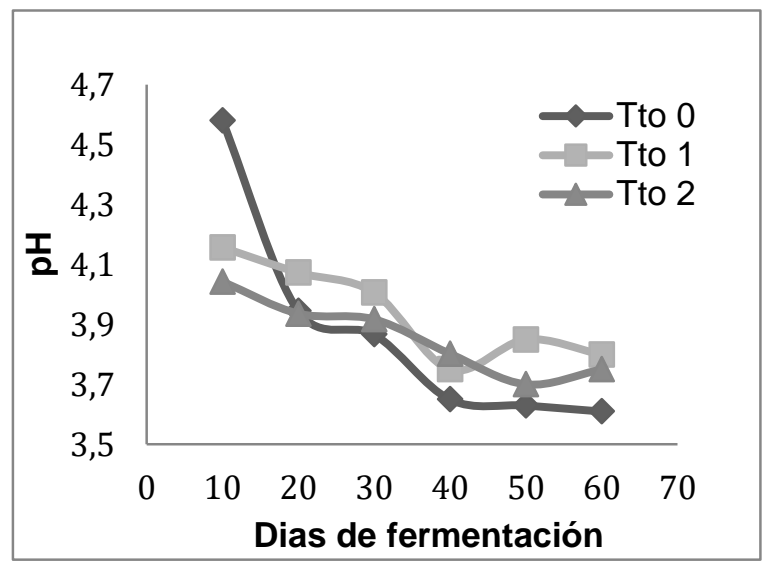

Figura 1. Perfil de $\mathrm{pH}$ por tratamiento fermentativo.

En la figura 1, es posible apreciar el comportamiento del $\mathrm{pH}$ en el medio fermentativo de cada tratamiento correspondiente al factor concentración de sustratos y el tiempo de secado. Para el tratamiento T0 se observa una disminución rápida del $\mathrm{pH}$ desde el inicio hasta el día 20 de fermentación, con un pH de 4,58 a 3,94, continuando con descensos paulatinos hasta el día 40 de fermentación con un valor de 3,6 donde se mantiene hasta el término de la fermentación. En los tratamientos T1 y T2 por el contrario desde los inicios se observan descensos paulatinos con pocas fluctuaciones en el valor del $\mathrm{pH}$; empezando en 4,15 hasta 3,8 para T1 y de 4,04 a 3,75 para T2; este comportamiento del pH puede estar dado a la producción de ácidos por las diferentes especies microbianas y a la acción de la concentración de sustratos que en cada uno de estos es adicionado, la disminución 
del $\mathrm{pH}$ ocurre a una velocidad menor posiblemente por la acción de sustratos que otorgan mayor estabilidad en la fermentación - la baja producción de ácidos por la variabilidad microbiana. En estudios realizados sobre recuento de flora bacteriana causante de los procesos de fermentación de almidón de yuca se ha encontrado que las bacterias acido lácticas como los lactobacillus son la población mayoritaria (Frederic Ampe et. al., 2001) (Inayara C.A et. al., 2005). Los Lactobacillus crecen bien en medios ligeramente ácidos, con $\mathrm{pH}$ inicial de 6,4- 4,5 y con un óptimo de desarrollo entre 5,5 y 4,2 . Su crecimiento cesa cuando el $\mathrm{pH}$ alcanza valores entre 3,6 y 4,0 y disminuye notablemente en medios neutros 0 ligeramente alcalinos (Ailade Jiménez, 2009).

Propiedades funcionales: El índice de solubilidad en agua (ISA) presento diferencias significativas $(p<0,05)$ respecto a los factores método de secado, días de fermentación y concentración de sustrato sobre el almidón agrio de yuca obtenido.

En la Figura 2, se observa que para el método de secado por humidificación M1 cada uno de los tratamientos tuvo una disminución en el índice de solubilidad, mientras que en la Figura 3 donde se describe el método de secado tradicional M2, solo se presenta este comportamiento en el tratamiento T0; los tratamientos $\mathrm{T} 1$ y T2 por el contrario presentaron un aumento en el índice de solubilidad a medida que incrementaban los días de fermentación.

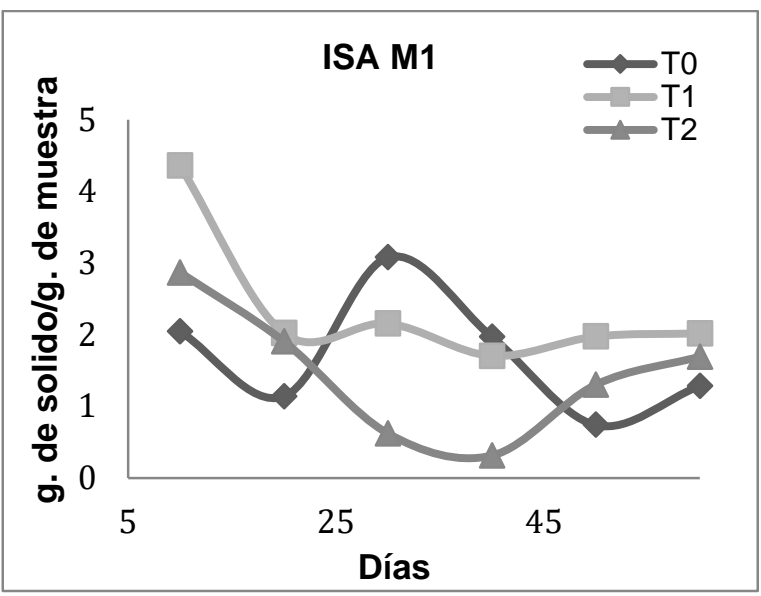

Figura 2. Resultados del Índice de solubilidad en agua con el método de secado 1.

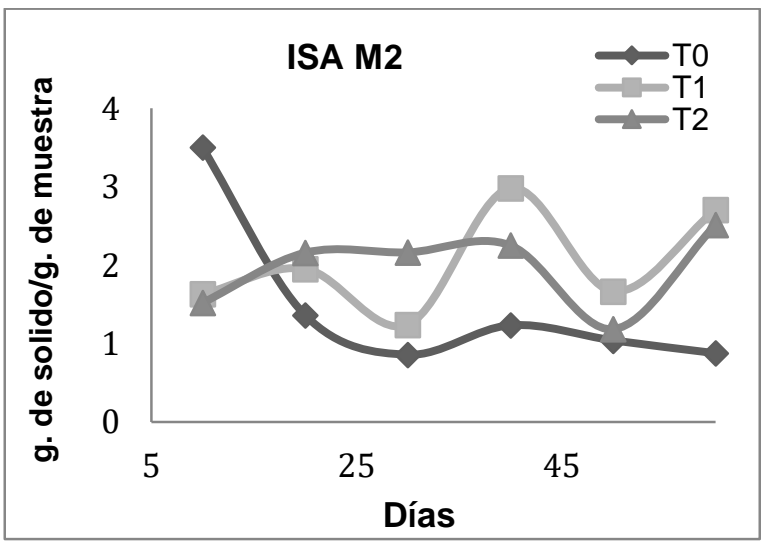

Figura 3. Resultados del Índice de solubilidad en agua con el método de secado 2 .

Estos cambios experimentados en las muestras finales de almidón de yuca dependieron en mayor medida por los factores días de fermentación y sustrato a un 
nivel de confianza del $95 \%$, el factor método de secado no presento influenciada directamente en la variable respuesta obtenida. La disminución del índice de solubilidad indica que se tiene un almidón de alta calidad, alta viscosidad, y alto poder hinchamiento (Fonseca \& Romero, 2012), por lo que el proceso de fermentación se presenta como una variable que mejora la funcionalidad de este, relacionado a un aumento en el contenido de amilo pectina, el cual se asocia a las variaciones del ISA ( Hwang \& Kokini , 2001).

Los mejores tratamientos obtenidos en el M1 fue de $0,74 \mathrm{~g}$ de solido/ $\mathrm{g}$ de muestra en el tratamiento T0 día 50 y para M2 0,86 tratamiento T0 día 30. Valores similares son reportados por (Aristizabal \& Sanchez, 2007) para almidones de yuca sin ningún tipo de tratamiento, variando el índice entre 0,27 $12,32 \mathrm{~g}$ solido/g muestra.

El índice de absorción en agua (IAA) presento diferencias significativas respecto a los días de fermentación y concentración de sustrato $(p<0,05)$. A demás, las interacciones entre los factores días de fermentación*concentración de sustrato y días de fermentación*método de secado fueron significativos con un nivel de confianza del $95 \%$.

En la Figura 4, se evidencia una disminución paulatina del índice de absorción, alcanzando mayores valores a medida que aumentan los días de fermentación hasta el último día para el método de secado $\mathrm{M} 1$; en la Figura 5, se muestra el comportamiento del IAA en el método M2 con un descenso paulatino al igual que en $\mathrm{M} 1$, pero para este caso se obtienen valores más bajos de IAA en los últimos días.

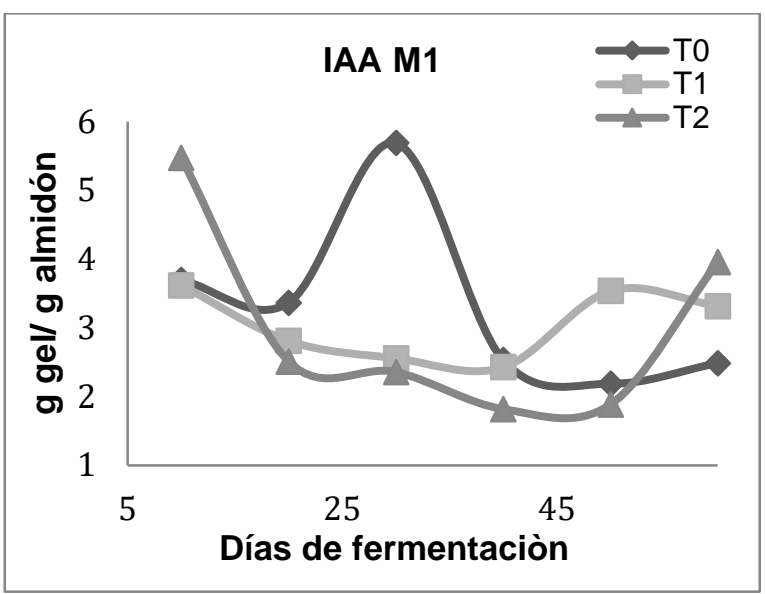

Figura 4. Resultados del Índice de absorción (IAA) en agua con el método de secado 1.

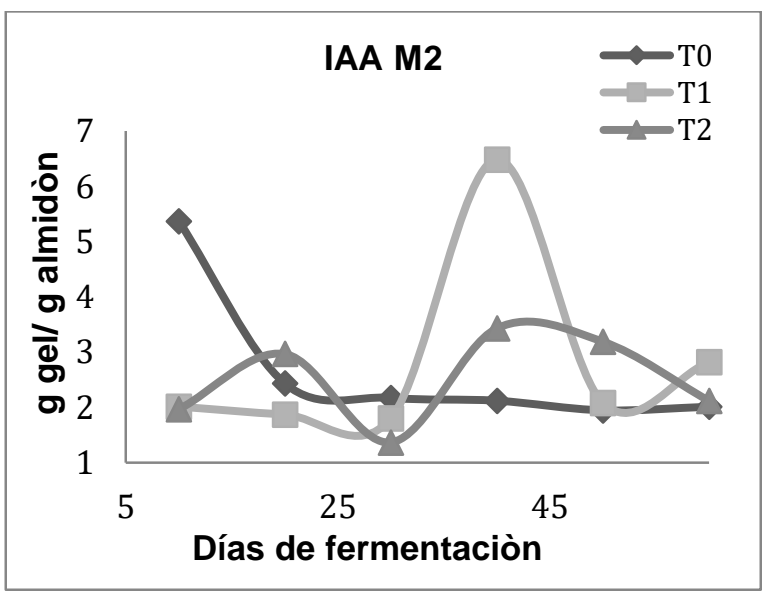

Figura 5. Resultados del Índice de absorción (IAA) en agua con el método de secado 2 . 
Para ambos métodos de secado, los días de fermentación fueron un factor a destacar que incidió directamente con la disminución del índice de absorción. Una baja absorción de agua puede indicar que el almidón es de baja calidad, ya que tiende a producir pastas delgadas y de poca estabilidad. Sin embargo, un IAA muy elevado puede hacer que las propiedades mecánicas de la masa se vean afectadas de forma negativa (Bernabé, S.F). Los valores de nuestro estudio concuerdan con otros trabajos de investigación, donde se afirma que el índice de absorción de agua en el almidón de yuca varía entre 0.82 y $15.52 \mathrm{~g}$ gel $/ \mathrm{g}$ muestra y que la aplicación de sustratos como JG y EL modifican los enlaces de hidrógeno y covalentes, los cuales son los responsables del grado de asociación intermolecular entre los polímeros amiláceos (Diniz, 2006). Los valores reportados en este estudio para IAA, pueden ser usados en productos alimenticios, los tratamientos que se encuentran entre 3,29 a $3,51 \mathrm{~g}$ gel/g muestra se recomiendan para mezclas en polvo, sopas instantáneas, mezclas para panificación, bebidas instantáneas (Sanchez, 2007; Alvis , Vélez, Villada, \& Mendoza , 2007) y aquellos en $3,04 \mathrm{~g} \mathrm{gel} / \mathrm{g}$ muestra se usan para mezclas para natillas y salsas (Cerón, Guerra, Legarda, Enriquez, \& Pismag, 2016)
En el poder de hinchamiento $(\mathrm{pH})$ Los días de fermentación y método de secado, presentaron diferencias significativas en cada uno de los tratamientos $(p<0,05)$. En las Figuras 6 y 7 se describen los resultados del análisis realizado en el almidón para determinar el poder de hinchamiento, valores similares se reportan en el estudio de (Aristizabal \& Sanchez , 2007) variando entre 0,79 y $15,45 \mathrm{~g}$. de agua / g. de almidón. El poder de hinchamiento se relaciona con la capacidad de adsorción de agua del almidón presente. Generalmente estos en su forma nativa son insolubles en agua por debajo de su temperatura de gelatinización, muy relacionada al contenido de amilopectina, siendo la amilosa un diluyente e inhibidor del hinchamiento (CHENG , TSAI, \& TSENG, 1996).

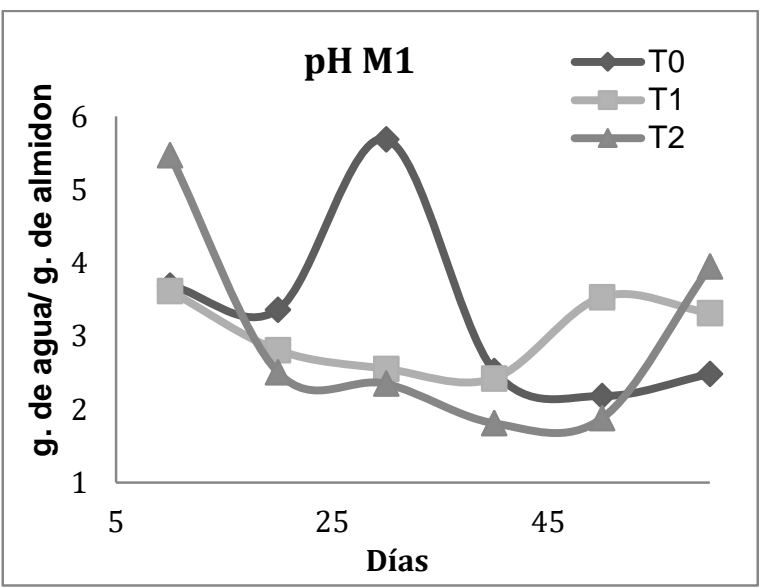

Figuras 6. Resultados del poder de hinchamiento $(\mathrm{pH})$ en agua con el método de secado 1. 


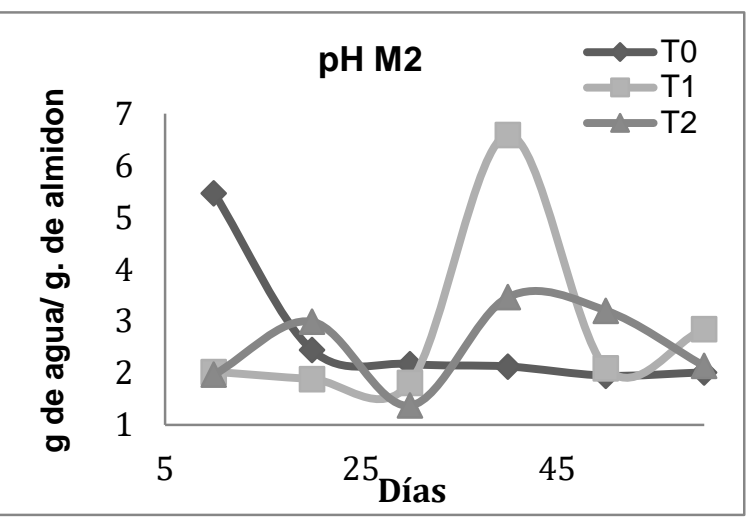

Figuras 7. Resultados del poder de hinchamiento $(\mathrm{pH})$ en agua con el método de secado 2 .

Capacidad de expansión: En la evaluación de capacidad de expansión del almidón se presentaron diferencias significativas respecto a los días de fermentación y la concentración de sustratos $(p<0,05)$ específicamente. A demás, las interacciones entre los factores días de fermentación*concentración de sustrato y días de fermentación*método de secado fueron significativos con un nivel de confianza del 95\%.

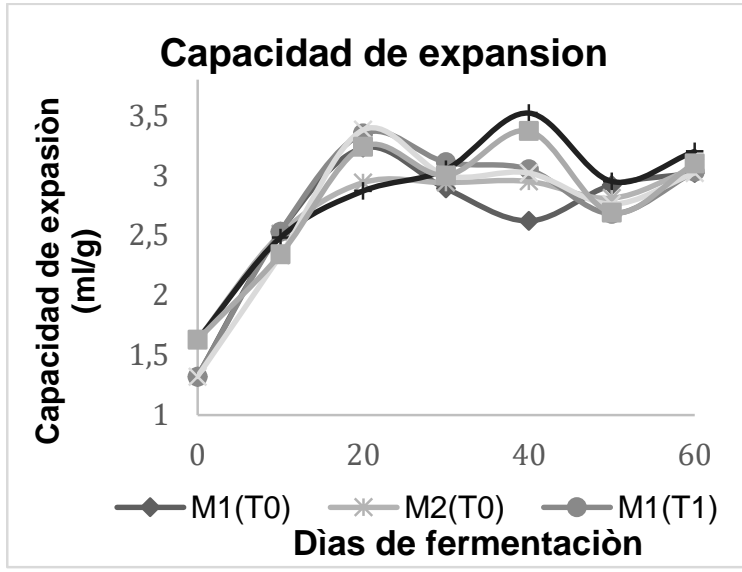

Figura 8. Variación de la capacidad de expansión con respecto al método de secado en los distintos tratamientos

En la Figura 8 se puede observar que el tratamiento T0 presento el menor volumen de expansión al finalizar el proceso fermentativo, correspondiendo este al tratamiento donde no fue adicionado sustratos al medio, denotándose en este comportamiento la influencia que posee la adición de sustratos en el aumento de la capacidad de expansión del almidón. El mayor volumen de expansión en todo el tiempo de fermentación se obtuvo en el día 20 para el tratamiento T2 y en el día 40 para el tratamiento T1. También fue posible observar pequeñas fluctuaciones en los resultados de expansión, como en el día 50 donde hubo una disminución drástica para los tres tratamientos, que pudo estar relacionada con la influencia de otros factores como los cambios en las condiciones climáticas durante el secado, el crecimiento de los microorganismos que podría estar siendo inhibido por el $\mathrm{pH}$, la formación de metabolitos secundarios o la degradación del almidón por microorganismos no lácticos que pueden causar alteraciones ( Cadena, Villarraga, Deivis, \& salcedo, 2006).

También, se evidenciaron diferencias entre las concentraciones de sustratos utilizadas 
en la fermentación (tratamiento T1 y T2) en donde a partir del día 30 el almidón fermentado por la concentración correspondiente al tratamiento $\mathrm{T} 1$ se mantuvo con un volumen de expansión superior al del tratamiento T2, continuando con mejores volúmenes hasta terminado el proceso fermentativo. Aspecto que también nos permite tener en consideración la cantidad de sustratos optima que debe ser adicionada para mantener un equilibrio en la fermentación sin entrar en una sobresaturación de sustratos, mejorando la calidad del almidón y obteniendo resultados favorables en tiempos más cortos.

El método de secado con humidificación presento el mayor volumen de expansión del almidón a lo largo de toda la fermentación, este resultado corresponde al día 20 por el tratamiento T2; resultados que se relacionan con los obtenidos por (Brabet, Chuzel, Dufour, Raimbault, \& Giraud) estos manifiestan que obtuvieron mejores resultados en la capacidad de expansión de almidones secados por el método de humidificación que por el método de secado tradicional. sin embargo, esto cambia a partir del día 40 al 60 en donde el método M2 mejora la capacidad de expansión del almidón con resultados superiores al método M1. Estos cambios están relacionados con dos variables que hacen parte del secado del almidón que son el tiempo de secado (min.) y la radiación, que mide la intensidad de energía solar emitida en el ambiente.

Las interacciones entre los factores días de fermentación, concentración de sustratos y método de secado presentaron diferencias significativas sobre el tiempo de secado. En donde se registran mayores tiempos de secado en los días 40 y 60 de fermentación para cada concentración de sustratos; además, entre la interacción días de fermentación*método de secado los tiempos de secado aumentan para los dos métodos en esos mismos días de fermentación, siendo superior el tiempo correspondiente al método de secado con humidificación e incluso entre la interacción concentración de sustratos*método de secado el tiempo de secado siempre se mantuvo superior para el método M1. De cada uno de estos comportamientos entre los factores se puede inferir una relación entre las variables tiempo de secado y capacidad de expansión, debido a que las disminuciones en los volúmenes de expansión del almidón obtenidas a lo largo del diseño están siendo afectadas por los aumentos en el tiempo de secado. El tiempo de secado promedio óptimo del almidón tiene una duración aproximada entre 360 a 420 minutos; pudiendo alcanzar hasta un máximo de 8 horas de secado o 480 minutos tal como se describe por (Dufour, Brabet, Zakhia, \& Chuzel, 1995) y alteraciones en estos tiempos podrían ocasionar un 
fraccionamiento parcial del granulo de almidón, como consecuencia la firmeza interna del granulo disminuye y se debilita la estructura del almidón que permite que su capacidad de expansión aumente durante el horneo.

Los aumentos en el tiempo de secado del almidón en los días de fermentación correspondientes a su vez se encuentran relacionados con la radiación una variable de medición en la que las interacciones entre los factores no fueron significativas. No obstante, el factor días de fermentación si presentó diferencias sobre la radiación; teniendo en cuenta que para la obtención de almidón agrio de calidad el sol es un factor determinante, los secados debían realizarse solo cuando se encontraba con gran potencial de energía solar en el ambiente; por tanto en los días donde aumentaba el tiempo de secado seguidamente se registraba una disminución en la medida de la radiación y viceversa. Un caso muy particular se registró en el día 20 de fermentación, este día el valor de la radiación fue el más alto en comparación con los demás ciclos de secado y se registra con un tiempo de secado optimo; como respuesta directa se obtuvo un resultado favorable en la expansión del almidón.

\section{CONCLUSIONES}

La adición de sustratos al medio y el método de secado ejercieron un efecto significativo en el proceso fermentativo del almidón agrio de yuca $(p<0,05)$. A través, de la elaboración de un producto de panificación de tipo pandebono se corrobora el aumento de la capacidad de expansión del almidón. Así mismo, los aumentos en el poder de hinchamiento descritos al final de la fermentación para los tratamientos con adición de sustratos T1 y T2. En condiciones óptimas de secado el método por humidificación M1 presento mejores resultados en el volumen de expansión en comparación con el método tradicional M2.
El tratamiento T2 presento el mayor volumen de expansión en el menor tiempo de fermentación con un resultado de $3.38 \mathrm{ml} / \mathrm{gr}$ para el día 20 de fermentación. Por último, el método de secado M1 favoreció la disminución en el índice de solubilidad de agua en el almidón agrio de yuca obtenido al final de la fermentación por cada uno de los tratamientos aplicados. Los resultados obtenidos nos permiten sentar algunas bases para procesos de estandarización y mejora del proceso productivo y calidad final del almidón agrio de yuca para la industria panadera y afines. 


\section{BIBLIOGRAFIA}

Ailade Jiménez serna, Efectos de diferentes fármacos sobre el crecimiento de la Lactobacillus Casei Shirota, tesis Doctoral en Ciencias Instituto Politécnico Nacional (escuela nacional en ciencias biológicas) México 2009. pag.13

Alarcon M, F., \& Dufuor, D. (s.f.). Almidon agrio de yucca en Colombia. Tomo1: Producción y recomendaciones. Cali: CIAT.

Alvis , M., Vélez , C., Villada, H., \& Mendoza , M. (2007). Análisis físico-químico y morfológico dealmidones de ñame, yuca y papa y determinación de la viscosidad de las pastas. Información Tecnológica, Volumen 19 No1, p. 19-28.

Anderson, R., Conway, H. F., Pheiser, V. F., \& Griffin, E. L. (1969). Gelatinisation of corn grits by roll and extrusion cooking. Cereal Science Today, 14:4-12.

Aquino, A., Pereira, J., Watanabe, L., \& Amante, E. (2013). Standardisation of the sour cassava starch reduces the processing time by fermentation water monitoring. International Journal Of Food Sciencie \& Technology, 1892-1898.
Aristizabal , J., \& Sanchez, T. (2007). Guía técnica para la producción y análisis de almidón de yuca. . Italia: Organización de las naciones unidas para la agricultura y la alimentación.

Ascheri D, P. R., \& Vilela E, R. (1995). Alteracoes do polvilho de mandioca pela fermentacao, no fabrico de biscoito. Pesquisa Agropecuaria Brasileira, 30(2), 269-279.

Bedolla , S., \& Rooney, L. W. (1984). Characteristics of US and Mexican instant maize flours for tortilla and snack preparation. Cereals Food World, 29(11): 732-735.

Bernabé, C. (S.F). Influencia de los componentes de la harina en la panificación. Obtenido de http://www.indespan.com/userfiles/file/Mi crosoft\%20Word\%20\%20articulo\%20panorama\%20panaderoalmidon.pdf.

Bertolini, A. C., Mestres, C., Raffi, J., Buléon, A., Lerner, D., \& Colonna, P. (2001). Photodegradation of cassava and corn starches. Journal of agricultural and food chemistry, 49(2), 675-82. 
Brabet, C., Chuzel, G., Dufour, D., Raimbault, M., \& Giraud, a. J. (s.f.). Improving cassavsa sour starch quality in colombia. Cassava Flour and Starck Progress in Research and Development, $241-246$.

Cadena, M., Villarraga, E., Deivis , L., \& salcedo , J. (2006). Evaluación de la agroindustria del almidón agrio de yuca (Manihot esculenta, Crantz) en Córdoba y Sucre. Temas Agrarios, 11.

Cerón, C., Guerra, L., Legarda, J., Enriquez, M., \& Pismag, J. (2016). Efecto de la extrusión sobre las características físicoquímicas de harina de quinua (chenopodium quinoa willd). Revista Facultad de ciencias agrarias.

Cheng , Y., Tsai, M., \& Tseng, K. (1996). Effect of amylose content on the rheological property of rice starch. Cereal Chemistry, v. 73 , n. 4 , p. $415-420$.

Diniz, I. P. (2006). Gerais, Caracterizacáo tecnológica do polvilhoazedoproducido em diferentes regióes do Estado de Minas. Brasil: Universidade Federal de Viçosa. Programa de Pós-Graduacáo em Ciência e Tecnología de Alimentos, Viçosa, Minas Gerais: Tesis de maestría.

Dufour, D., Brabet, C., Zakhia, N., \& Chuzel, G. (1995). Influence de la fermentation et du séchage solaire sur l'acquisition du pouvoir de panification de l'amidon aigre de manioc. Transformation Alimentaire du Manioc., 402 - 415.

Frederic Ampe, Audrey Sirven, Nadine Zakhia. Dynamics of the microbial community responsible for traditional sour cassava starch fermentation studied by denaturing gradient gel electrophoresis and quantitative RNA hybridization. International Journal of food Microbiology (2001).pag.45-54.

Fonseca, K., \& Romero, J. (2012). Evaluación de harinas precocidas y no precocidas de clones promisorios de papa criolla Solanum tuberosum. Grupo phureja para aprovechamiento industrial.

Hwang, J., \& Kokini , L. (2001). Contribution of the side branches to rheological properties of pectins. Carbohyd. Polym, 19(1):41-50.

Inayara C.A. Lacerda a, Rose L .Miranda a, Beatriz M. Borelli a, Álvaro C. Nunez b, Regina M.D. Nardia, Marc Andres Lachase c, Calos A. Rosa. Lactic acid bacteria and yeasts associated with spontaneous fermentation during the production of sour cassava starch in Brazil, International Journal of food Microbiology 105 (2005), pag.213-219.

Kobawila, S., Louembe, D., Keleke, s., Hounhouigan, J., \& Gamba, C. (2005). 
Reduction of the cyanide content during fermentation of cassava roofs and leaves to produce bikedi and ntaba mbodi , two food productsfrom congo. African Journal of biotechnology, 4, 689-696.

Lopez Marin, R. (2011). Efectode la fermentacion y el secado sbre la obtencion de almidon agrio apartir de dos variedades de yuca( Manihot esculenta). Universidad de Costa Rica .

Marcon M, J., Kurtza, D., \& Raguzzoni, J. (2009). Expansion properties of sour cassava starch (polvilho azedo): variables related to its practical application in bakery. Starch/St€arke, 61, Starch/St€arke,, 716-726.

Marcon, M. A. (2004). Efeito do processo fermentativo pelo método tradicional e com adição de glicose, sobre a qualidade do polvilho azedo. Dissertação Magister Scientiae.Universidade Federal de Santa Catarina., 149.

Maria, M., Gisele, N., Krina, D. s., Santos, K., Manoela, A., Renata, C., y otros. (2007). Effect of the improved fermentation on physicochemical properties and sensorial acceptability of sour cassava starch. Brazilian Archives of Biology and technology, 50, 1073-1081.

Ramirez Ascheri, D. P., \& Rivero Vilela , E. (1995). Alteracoes do polvilho de mandioca pela fermentacao, no fabrico de biscoito. Pesquisa Agropecuaria Brasileira, 30, 269-279.

Rincon Suarez, L. M., \& Villamil Novoa , F. A. (2005). Obtencion y caracterizacion fisicoquimica y microbiologica del almidon agrio para el mejoramiento del procesos de fermentacion. Universidad industrial de Santander.

Sanchez, I. (2007). Propiedades fisicoquímicas de almidones catiónicos elaborados por. Instituto Politécnico Nacional., México. D. F. 